\title{
Alterations of Oximetry-Derived Perfusion Index in Neonatal Brachial Plexus Injury
}

\author{
(D) Emre Dincer ${ }^{1}$, (1) Sevilay Topçuoğlu¹, (1) Adil Umut Zübarioğlu², (1) Güner Karatekin¹
}

1University of Health Sciences Turkey, Zeynep Kamil Maternity and Children Training and Research Hospital, Clinic of Neonatology, istanbul, Turkey 2istinye University Faculty of Medicine, Department of Pediatrics, Division of Neonatology, İstanbul, Turkey

\begin{abstract}
Aim: As we know, the perfusion index (PI) increases in nerve blocked areas in regional anesthesia and this is used to predict successful intervention, we hypothesized that, in neonatal brachial plexus palsy (NBPP), PI may alter in the affected arm.

Materials and Methods: Prospectively, 11 patients with defective Moro reflex diagnosed as NBPP were included in this study. Their demographic data were collected and perfusion indices were measured from both the affected and non-affected limbs in the $24^{\text {th }}$ hour of postnatal life. These measurements were statistically compared. The increased rate of PI was also calculated and the increment of PI in patients with and without clavicle fracture was compared.

Results: PI values were statistically higher in affected extremities compared to not-affected extremities (mean \pm standard deviation, $2.47 \pm 0.74$, $1.83 \pm 0.66$ respectively, $p=0.0003)$. There was no difference in patients with or without clavicle fracture.

Conclusion: In the future, PI may be evaluated as a prognostic factor for neurologic dysfunction in NBPP and be used as a predictor for early surgical intervention.
\end{abstract}

Keywords: Perfusion index, neonatal brachial plexus injury, newborn, peripheral nerve

\section{Introduction}

Neonatal brachial plexus palsy (NBPP) is uncommon with an incidence of $0.05-0.3 \%$ but it can cause permanent functional problems in up to $20-30 \%$ of affected individuals (1). Even though many risk factors have been widely investigated, no antepartum or intrapartum risk factors have been reported to be reliable except for shoulder dystocia. Consequently, NBPP is still regarded as a nonpredictable situation (2).

Although NBPP is easily recognizable in infants with loss of Moro reflex or movements in the affected extremity, different diagnostic modalities such as electromyography, magnetic resonance imaging, and ultrasonography are needed to investigate its localization, severity, and prognosis. However, these diagnostic tools need highly qualified personnel, expensive equipment, and even anesthetic interventions ranging from sedation to general anesthesia, which may cause complications (3).

Perfusion index $(\mathrm{Pl})$ is a non-invasive marker of pulse strength provided by new generation pulse-oximeters. It is calculated as the ratio of pulsatile and non-pulsatile blood flow and is related to cardiac output and tissue vascular resistance (4). Previously, it has been suggested that lower values of PI values are associated with neonatal pathologies 
caused by hypoperfusion (5) and correlate with disease severity (6).

Given its efficacy, the use of PI has been investigated in different conditions such as the screening for congenital heart diseases (7), patent ductus arteriosus (8), and tissue perfusion after red blood cell transfusions (9), and it has been reported to be an effective parameter.

Recent studies in adults have reported that PI, measured on the extremities after central and peripheral nerve blocks, increased due to vasodilation as a result of the cessation of alpha-adrenergic stimuli during regional anesthesia (10).

$\mathrm{PI}$ is an easy, fast, and user-independent measurement. We hypothesized that PI values may be higher on the affected extremity due to the cessation of $\alpha$-adrenergic stimuli as a result of nerve injury in NBPP.

\section{Materials and Methods}

This prospective observatory study was conducted in a tertiary Maternity and Children's Training and Research Hospital between January 2016 and July 2017. Local Ethics Committee approval was received from University of Health Sciences Turkey, İstanbul Zeynep Kamil Women and Children Diseases Training and Research Hospital (approval no: 136, date: 24.06.2016) and written informed consent was obtained from all patients. Babies with defective Moro reflex in one limb or "waiter's tip" posture diagnosed with NBPP were included in the study. Those babies who had a limited range of movement (thought to be affected in utero or by other musculoskeletal problems), cardiovascular or respiratory impairment, birth asphyxia $(\mathrm{pH}<7.1$ or base excess $>12$ ), sepsis, or congenital anomalies including congenital heart diseases were excluded from this study.

Those babies diagnosed with NBPP were evaluated via chest X-ray for clavicle fracture. On the $24^{\text {th }}$ hour of postnatal life, the baby's oxygen saturation, heart rate, arterial pressures, and PI were recorded on both their right and left upper extremities.

Their demographic data such as gestational age, birth weight, maternal age and type of delivery, and usage of auxiliary birth instruments were recorded.

The values of the affected limb were compared with other extremity values. To test our main hypothesis that PI is higher in the arm with palsy, we used pairwise Student's t-test to identify if there was a difference between the affected and unaffected arms of the same patient. To explore further, if the fracture had a different impact rather than just brachial plexus injury, we calculated the
PI difference ratios between the affected and unaffected sides. Following this, we compared these ratios between the patient groups with and without clavicle fracture again via Welch's two sample t-test. A two-sided p-value smaller than 0.05 was accepted as significant.

\section{Results}

Fifteen patients were diagnosed as NBPP during the study period and four of them were excluded from the study due to a diagnosis of birth asphyxia. The median gestational age was 40 weeks (Q1: 38 - Q3: 40 weeks) and the median birth weight was 4,050 grams (Q1: 3,810 - Q3: 4,360 grams) (Table I). In seven babies, NBPP was on the left side and in four patients, NBPP was on the right extremitie. In eight patients, there was a loss of Moro reflex and in three of the patients, Moro reflexes were weak. All babies had higher PI levels on the extremity with NBPP, independent of being right (preductal) or left (postductal). The clinical features and $\mathrm{PI}$ measurements of the patients are given in Table II. The $\mathrm{Pl}$ measured on the side with palsy [mean \pm standard deviation (SD): $2.47 \pm 0.74$ ] was significantly higher than for the unaffected arm $(1.83 \pm 0.66) ;[t(10)=5.25, p=0.0003]$. The ratio of PI differences was not statistically different between the group with brachial plexus only (mean \pm SD: $25.68 \pm 13.42$ ) and the group with clavicle fracture (mean \pm SD: $22.94 \pm 14.16) ;[t(8)=0.31, p=0.76]$.

\section{Discussion}

In this study, we hypothesized that the nerve injury in NBPP may cause vasodilatation in the affected arm of the neonate and this can be shown with PI measured by a pulse-oximeter. We found statistically significant increased $\mathrm{Pl}$ values in the affected extremities of the neonates.

\begin{tabular}{|l|l|}
\hline \multicolumn{2}{|l|}{ Table I. Demographic features of the patients } \\
\hline & Patients (n=11) \\
\hline Gestational age (weeks) & $40^{*}$ (Q1-Q3; 38-40) \\
\hline Birth weight (grams) & $4050^{*}$ (Q1-Q3; 3810-4360) \\
\hline Gender (n) & $\begin{array}{l}\text { Female: 4 (36\%) } \\
\text { Male: } 7(64 \%)\end{array}$ \\
\hline Delivery mode (n) & $\begin{array}{l}\text { Vaginal: } 10(91 \%) \\
\text { Cesarean: 1 (9\%) }\end{array}$ \\
\hline Affected extremity (n) & $\begin{array}{l}\text { Left: 7 (64\%) } \\
\text { Right: 4 (36) }\end{array}$ \\
\hline Clavicle fracture (n) & $6(54 \%)$ \\
\hline $\begin{array}{l}\text { Values not normally distributed are given as median and quartile 1-3 and } \\
\text { marked with* }\end{array}$ \\
\hline
\end{tabular}


Table II. Clinical features and perfusion index measurements of patients

\begin{tabular}{|c|c|c|c|c|c|c|c|}
\hline & $\begin{array}{l}\text { Gestational } \\
\text { age }\end{array}$ & $\begin{array}{l}\text { Birth } \\
\text { weight }\end{array}$ & $\begin{array}{l}\text { Affected } \\
\text { limb }\end{array}$ & $\begin{array}{l}\text { Moro reflex on } \\
\text { affected side }\end{array}$ & $\begin{array}{l}\text { Clavicle } \\
\text { fracture }\end{array}$ & $\begin{array}{l}\text { Perfusion index on } \\
\text { affected extremity }\end{array}$ & $\begin{array}{l}\text { Perfusion index on non- } \\
\text { affected extremity }\end{array}$ \\
\hline Baby 1 & 40 & 4440 & Left & No & Yes & 1.1 & 0.55 \\
\hline Baby 2 & 34 & 2670 & Left & No & Yes & 1.6 & 1.3 \\
\hline Baby 3 & 37 & 3730 & Right & No & Yes & 2.4 & 1.8 \\
\hline Baby 4 & 41 & 4050 & Left & Weak & No & 3.2 & 1.8 \\
\hline Baby 5 & 39 & 3890 & Left & No & Yes & 2.4 & 2.1 \\
\hline Baby 6 & 36 & 3140 & Right & Weak & No & 1.9 & 1.3 \\
\hline Baby 7 & 40 & 4350 & Left & No & Yes & 2.8 & 1.5 \\
\hline Baby 8 & 41 & 4290 & Right & No & No & 2.8 & 2.6 \\
\hline Baby 9 & 40 & 4320 & Left & No & Yes & 2.5 & 2.2 \\
\hline Baby 10 & 39 & 3980 & Right & Weak & No & 3.8 & 2.9 \\
\hline Baby 11 & 40 & 4120 & Left & No & No & 2.7 & 2.1 \\
\hline
\end{tabular}

In previous studies, PI was widely investigated for detecting nerve blockage. Vasodilatation occurs in the nerve-blocked part of the body as a result of the cessation of $\alpha$-adrenergic stimuli (10). As there is no parasympathetic innervation of arteries/arterioles, blockage of the related nerve results in a loss of sympathetic tone below the level of the blockage and so vasodilatation occurs. With respect to this mechanism, it was investigated whether PI can be used to determine nerve blockage in regional anesthesia and if it is useful in different anesthesia modalities, such as infraclavicular and supraclavicular brachial plexus (1113).

PI has been shown to be an effective tool for evaluating perfusion (4). Studies about PI have shown that PI values are correlated with superior vena cava flow, which reflects the cerebral blood flow (14) and also with left ventricle output (15). Lower values of PI give information about hypoperfusion, so it can be used in screening for congenital heart diseases (5), detecting patent ductus arteriosus (8), or grading the severity of illness in neonates $(6,8)$. It is also reported that red blood cell transfusions provide increased PI (9) and surfactant treatment improves PI values (16).

PI can be affected by patent ductus arteriosus and studies have shown that in the first three days of life, PI values are lower in the left hand (postductal) than in the right hand (preductal) of the neonate (17). In our study, even though postductal PI levels (the left extremity) were expected to be lower than preductal PI levels (the right extremity) at the $24^{\text {th }}$ hour of life, it was observed that even if NBPP is on the left extremity of the neonate, PI levels are higher than in the unaffected extremity.
On the other hand, as aforementioned, PI has been used in evaluating the severity of neonatal illness (6) and has been correlated with cardiac output (15). However, in the light of our findings, in cases of NBPP, monitoring the neonate from the affected extremity may show higher levels of PI on pulse-oximeter. This situation may lead to issues with fluid replacement or inotrope therapies so it may be logical to consider measurements taken from the unaffected arm for treatment plans.

NBPP is still a problem in neonatal medicine, causing functional problems in one-fourth of affected neonates. Even though NBPP can be easily diagnosed via physical examination after birth, further studies need to be done to clarify the condition. The gold standard for the evaluation of the NBPP is electro-diagnostic studies. These studies have been shown to be superior to imaging studies regarding localization and severity. However, when it comes to the issue of determining prognosis or predicting the need for microsurgery, no single imaging study has been shown to be sufficient $(1,2,5,18)$. In addition to diagnostic studies, the presence of Horner syndrome or lower scores on the "Active Movement Scale" are predictors for early microsurgical intervention (19). Due to all this ongoing controversy, a combination of more parameters is helpful in the evaluation of NBPP. To evaluate the correlation of prognosis and increase in PI levels compared to the unaffected extremity, it was planned to follow-up the neonates in our study for three years. However, only three of the babies were brought to follow-up and it was not possible to calculate the correlation of increase in PI with prognosis. Pleasingly, all three of these patients had no disability in three years of follow-up. In future studies, we think that evaluating PI 
after the third day of life may eliminate the effect of ductus arteriosus in the left arm.

\section{Study Limitations}

One limitation of our study is that our sample size was small. Although the number of patients was small, we found significantly higher levels of PI in the affected limbs of the patients. Future studies are needed to evaluate the duration of $\mathrm{Pl}$ alteration and, its correlation with other diagnostic studies, and its usefulness in long-term followup.

\section{Conclusion}

In conclusion, PI levels are higher in the affected extremities of newborns with NBPP compared to the unaffected side but this finding needs to be studied to determine whether it has a correlation with prognosis and whether it can be used as a predictor for early microsurgical intervention. In the future, this finding may be combined with other diagnostic modalities if further studies are carried out.

\section{Ethics}

Ethics Committee Approval: Local Ethics Committee approval was received from University of Health Sciences Turkey, İstanbul Zeynep Kamil Women and Children Diseases Training and Research Hospital (approval no: 136, date: 24.06.2016).

Informed Consent: Written informed consent was obtained from all patients.

Peer-review: Extrenally and internally peer-reviewed.

\section{Authorship Contributions}

Design: E.D., S.T., Data Collection or Processing: E.D. Analysis or Interpretation: S.T., G.K., Literature Search: E.D., A.U.Z., G.K., Writing: A.U.Z.

Conflict of Interest: The authors declare that they have no conflict of interest.

Financial Disclosure: The authors declared that this study received no financial support.

\section{References}

1. Smith BW, Daunter AK, Yang LI, Wilson T). An Update on the Management of Neonatal Brachial Plexus Palsy-Replacing Old Paradigms: A Review. JAMA Pediatr 2018; 172:585-91. https:// doi.org/10.1001/jamapediatrics.2018.0124

2. Yang L). Neonatal brachial plexus palsy--management and prognostic factors Semin Perinatol 2014; 38:222-34
3. Selcen D. Neonatal brachial plexus palsy. UpToDate, Inc. https:// www.uptodate.com/contents/neonatal-brachial-plexus-palsy. Access date, December, 2020.

4. Piasek CZ, Van Bel F, Sola A. Perfusion index in newborn infants: a noninvasive tool for neonatal monitoring. Acta Paediatr 2014; 103:468-73.

5. Granelli AD, Ostman-Smith I. Noninvasive peripheral perfusion index as a possible tool for screening for critical left heart obstruction. Acta Paediatr 2007; 96:1455-9.

6. De Felice C, Latini G, Vacca P, Kopotic RJ. The pulse oximeter perfusion index as a predictor for high illness severity in neonates. Eur J Pediatr 2002; 161:561-2.

7. Siefkes H, Kair L, Tancredi D), et al. Oxygen Saturation and Perfusion Index-Based Enhanced Critical Congenital Heart Disease Screening. Am J Perinatol 2020; 37:158-65.

8. Nitzan I, Hammerman C, Fink D, Nitzan M, Koppel R, Bromiker $R$. The effect of patent ductus arteriosus on pre-ductal and post-ductal perfusion index in preterm neonates. Physiol Meas 2018; 20;39:075006.

9. Ibonia KT, Bada HS, Westgate PM, et al. Blood transfusions in preterm infants: changes on perfusion index and intermittent hypoxemia. Transfusion 2018; 58:2538-44.

10. Abdelhamid B, Emam M, Mostafa M, et al. The ability of perfusion index to detect segmental ulnar nerve sparing after supraclavicular nerve block. J Clin Monit Comput 2020; 34:1185-91.

11. inosar $Y$, Weiniger $C F$, Meroz $Y$, et al. Pulse oximeter perfusion index as an early indicator of sympathectomy after epidural anesthesia. Acta Anaesthesiol Scand 2009; 53:1018-26.

12. Abdelnasser A, Abdelhamid B, Elsonbaty A, Hasanin A, Rady A. Predicting successful supraclavicular brachial plexus block using pulse oximeter perfusion index. Br J Anaesth 2017; 119:276-80.

13. Kus A, Gurkan Y, Gormus SK, Solak M, Toker K. Usefulness of perfusion index to detect the effect of brachial plexus block. I Clin Monit Comput 2013; 27:325-8.

14. Takahashi S, Kakiuchi S, Nanba Y, Tsukamoto K, Nakamura T, Ito $Y$. The perfusion index derived from a pulse oximeter for predicting low superior vena cava flow in very low birth weight infants. I Perinatol 2010; 30:265-9.

15. Janaillac M, Beausoleil TP, Barrington KJ, et al. Correlations between near-infrared spectroscopy, perfusion index, and cardiac outputs in extremely preterm infants in the first $72 \mathrm{~h}$ of life. Eur / Pediatr 2018; 177:541-50.

16. Karadag N, Dilli D, Zenciroglu A, Aydin B, Beken S, Okumus N. Perfusion index variability in preterm infants treated with two different natural surfactants for respiratory distress syndrome. Am J Perinatol 2014; 31:1015-22.

17. Hakan N, Dilli D, Zenciroglu A, Aydin M, Okumus N. Reference values of perfusion indices in hemodynamically stable newborns during the early neonatal period. Eur J Pediatr 2014; 173:597-602.

18. Pitt M. Why wait 3 months before doing electromyography in obstetric brachial plexus lesions? Challenging the norm. Dev Med Child Neurol 2012; 54:682. https://doi.org/10.1111/j.14698749.2012.04326.x

19. Andersen J, Watt J, Olson J,Van Aerde J. Perinatal brachial plexus palsy. Paediatr Child Health 2006; 11:93-100. 